\title{
Inhibitory Effects and Surface Plasmon Resonance-Based Binding Affinities of Dietary Hydrolyzable Tannins and Their Gut Microbial Metabolites on SARS-CoV-2 Main Protease
}

\author{
Huifang Li," Feng Xu," Chang Liu, Ang Cai, Joel A. Dain, Dongli Li, Navindra P. Seeram, \\ Bongsup P. Cho, and Hang Ma*
}

Cite This: https://doi.org/10.1021/acs.jafc.1c03521

Read Online

ABSTRACT: Severe acute respiratory syndrome coronavirus (SARS-CoV-2) main protease (Mpro) inhibitors are considered as potential treatments for coronavirus disease 2019, and dietary polyphenols show promise in SARS-CoV-2 Mpro inhibition based on in silico studies. In the present study, we utilize a combination of biochemical-, surface plasmon resonance-, and docking-based assays to evaluate the inhibition and binding affinities of a series of tannins and their gut microbial metabolites on SARS-CoV-2 Mpro. The tested compounds $(2-50 \mu \mathrm{M})$ were hydrolyzable tannins, including ellagitannins (punicalagin and ellagic acid) and gallotannins (tannic acid, pentagalloyl glucose, ginnalin $\mathrm{A}$, and gallic acid), and their gut microbial metabolites, urolithins and pyrogallol, respectively. They inhibited SARS-CoV-2 Mpro (by $6.6-100.0 \%$ at $50 \mu \mathrm{M}$ ) and bound directly to the Mpro protein (with dissociation constants from $1.1 \times 10^{-6}$ to $5.3 \times 10^{-5} \mathrm{M}$ ). This study sheds light on the inhibitory effects of tannins and their metabolites on SARS-CoV-2 Mpro.

KEYWORDS: severe acute respiratory syndrome corona virus (SARS-CoV-2), coronavirus disease 2019 (COVID-19), main protease (Mpro), hydrolyzable tannins, gut microbial metabolites, binding affinity, surface plasmon resonance (SPR)

\section{INTRODUCTION}

The coronavirus disease 2019 (COVID-19) pandemic, caused by a novel severe acute respiratory syndrome coronavirus (SARS-CoV-2) detected in 2019, is the greatest threat to global public health. This is mainly due to the lack of targeted therapeutic agents as effective treatments for this disease. Since the emergence of the pandemic, several coronavirus enzymes and proteins have been proposed as druggable targets for COVID-19. Among these targets, the main protease of SARSCoV-2, also termed as 3-chymotrypsin-like protease (3CLpro) or main protease (Mpro), has gained immense research interest due to its pivotal biological functions in the virus life cycle and the absence of similar homologs in humans. ${ }^{1,2}$ SARSCoV-2 Mpro is a non-structural protein that breaks down the viral polyproteins to generate other non-structural proteins, namely, RNA-dependent RNA polymerase and helicase essential for viral replication. ${ }^{3,4}$

Published biological studies show that small molecules capable of blocking the activity of SARS-CoV-2 Mpro can lead to the inhibition of viral RNA replication, thereby exerting anti-viral effects. $^{1-3,5,6}$ Therefore, considerable research efforts have been directed to find SARS-CoV-2 Mpro inhibitors as potential treatments for COVID-19. Various computational docking methods at the early stages of the COVID-19 outbreak have led to identifying numerous small-molecule natural products from plants and functional foods as positive "hits" for screening of Mpro inhibitors. ${ }^{7,8}$ Examples include dietary polyphenols including phenolic acid, ${ }^{9}$ flavonoids (e.g., quercetin, kaempferol, and myricetin), ${ }^{10}$ flavones (e.g., apigenin, baicalin, and luteolin), ${ }^{11}$ chalcones (e.g., $4^{\prime}$ acetamidechalcones), ${ }^{12}$ and hydrolyzable tannins. ${ }^{13}$ However, few of these dietary phenolic compounds were evaluated in chemical or biological assays for their anti-SARS-CoV-2 Mpro activity. It is imperative to validate the computational results with experimental evidence. In the current study, we evaluated the inhibition capacity of a series of dietary hydrolyzable tannins and their gut microbial metabolites (Figure 1) on SARS-CoV-2 Mpro activity using a maltose-binding protein (MBP)-tagged SARS-CoV-2 Mpro fluorescent assay. In addition, we developed a label-free and biosensor-based surface plasmon resonance (SPR) assay to measure direct binding parameters between the test compounds and SARSCoV-2 Mpro protein, which were further studied by molecular docking experiments. Combining the biochemical assay, biophysical-based binding assays, and computational approach can provide useful insights for understanding the effects of hydrolyzable tannins and their metabolites on SARS-CoV-2 Mpro.

Received: June 11, 2021

Revised: August 27, 2021

Accepted: August 31, 2021 
Ellagitannin

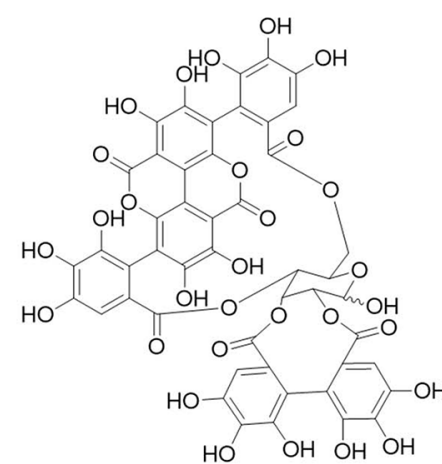

PA

\section{Gallotannin}

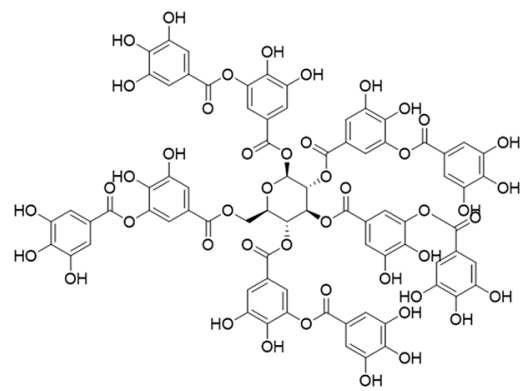

TA

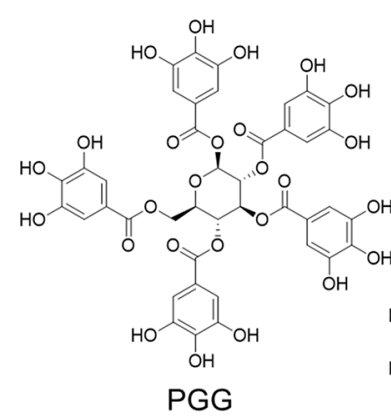

hydrolysis

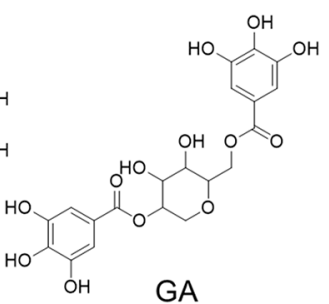

Structure unit/metabolite<smiles>O=C1Oc2c(O)c(O)cc3c2c(=O)oc2c(O)c(O)cc1c23</smiles><smiles>O=c1occc2ccc(O)cc12</smiles>

JA<smiles>Oc1ccc2c(c1)oc1ccccc12</smiles><smiles>O=C(O)c1cc(O)c(O)c(O)c1</smiles>

GLA gut microbial metabolism<smiles>Oc1cccc(O)c1O</smiles>

PYG

Figure 1. Chemical structures of dietary hydrolyzable tannins including ellagitannins (PA and EA) and gallotannins (TA, PGG, GA, and GLA) and their gut microbial metabolites UA, UB, and PYG as well as UA's phase II conjugate, mUA.

\section{MATERIALS AND METHODS}

Chemical Reagents and Materials. An MBP-tagged 3CL protease (SARS-CoV-2) assay kit was purchased from BPS Bioscience (San Diego, CA, USA). Urolithin A (UA), methylated urolithin A (mUA), and urolithin B (UB) were synthesized by our laboratory using reported methods. ${ }^{14-16}$ Pentagalloyl glucose (PGG) from winged sumac (Rhus copallinum) fruits ${ }^{17}$ and ginnalin A (GA) from red maple (Acer rubrum) leaves ${ }^{18}$ were previously isolated by our laboratory. Tannic acid (TA), gallic acid (GLA), pyrogallol (PYG), punicalagin (PA), ellagic acid (EA), and quercetin were purchased from Sigma-Aldrich Co. (St. Louis, MO, USA). The MBP-tagged 3CL protease (SARS-CoV-2) assay kit (catalog \#79955-1) was obtained from BPS Bioscience (San Diego, CA, USA). SPR experimental materials including the sensor chips (CM5 and PEG chips), amine coupling kit, glycine 2.0 buffer $(10 \mathrm{mM}$ glycine- $\mathrm{HCl}$ at $\mathrm{pH} 2.0)$, HBSEP buffer (0.1 M HEPES solution, $1.5 \mathrm{M} \mathrm{NaCl}, 30 \mathrm{mM}$ EDTA, $0.005 \%$; v/v; surfactant P20), acetate ( $10 \mathrm{mM}$ sodium acetate, $\mathrm{pH} 4.5$ and 5.0), and $50 \mathrm{mM}$ sodium hydroxide were purchased from Cytiva (Marlborough, MA, USA).
SARS-CoV-2 Mpro Enzyme Inhibition Assay. The inhibitory effects of hydrolyzable tannins and their gut microbial metabolites against SARS-CoV-2 Mpro activity were evaluated using an assay kit consisting of recombinant Mpro with an MBP-tag, protease substrate, assay buffer, and a positive control (GC376). This kit measures the activity of 3CL protease using an MBP-tagged recombinant enzyme, which catalyzes the cleavage of a fluorogenic protease substrate, in a homogeneous assay without time-consuming washing steps. When the protease substrate is cleaved by $3 \mathrm{CL}$ protease enzyme, it emits fluorescent signals that can be recorded at wavelengths of $360 / 460$ $\mathrm{nm}$ (excitation/emission, respectively). The activity of the $3 \mathrm{CL}$ protease enzyme can be calculated by comparing the fluorescent intensity of test samples and the blank control. The inhibition assay was conducted following the manufacturer's instructions. Briefly, a mixture of main protease $(30 \mu \mathrm{L})$ and test sample $(10 \mu \mathrm{L})$ at various concentrations was incubated in a 96-well black plate at room temperature for $30 \mathrm{~min}$. Then, the main protease substrate $(10 \mu \mathrm{L})$ was added to each well and the plate was sealed to initiate the reaction. The reaction mixture was kept at room temperature for $12 \mathrm{~h}$ 
(A)

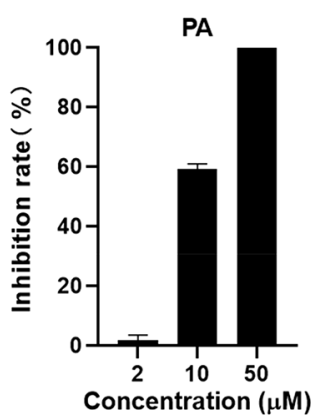

(C)

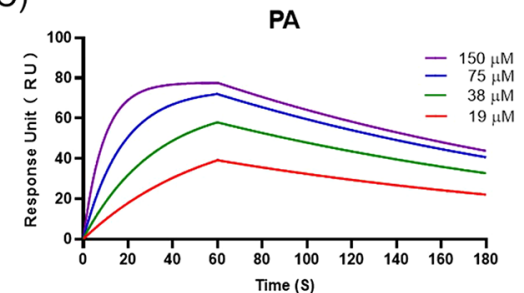

(B)

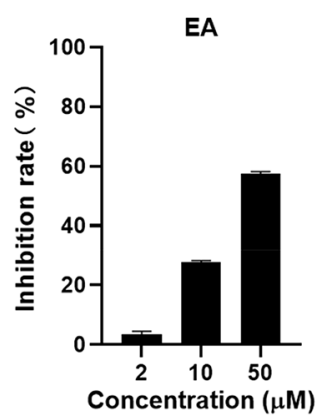

(D)

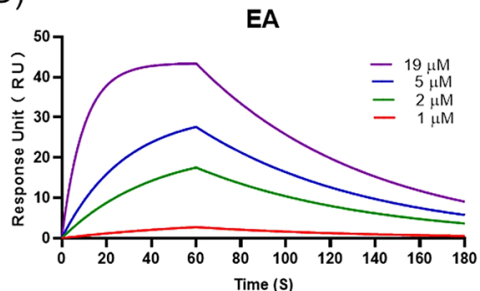

Figure 2. Inhibitory effects of ellagitannins PA and EA (at concentrations of 2, 10, and $50 \mu \mathrm{M}$ ) on SARS-CoV-2 Mpro enzyme activity by an MBPtagged SARS-CoV-2 Mpro protease assay kit (A and B). SPR sensorgrams of PA and EA characterizing their direct binding capacity with the SARSCoV-2 Mpro protein (C and D).

followed by measuring the fluorescence intensity of each well using a plate reader (SpectraMax M2, Molecular Devices Corp.; Sunnyvale, CA, USA) at an excitation and emission wavelength of 360 and 460 nm, respectively.

Surface Plasmon Resonance (SPR) Binding Assay. The binding affinities between test samples and SARS-CoV-2 Mpro protein were obtained from a biosensor-based SPR assay using a Biacore T200 instrument (GE Healthcare; Marlborough, MA, USA). A lyophilized recombinant Mpro protein from coronavirus (purchased from Sigma Aldrich; catalog \#SAE0172; $1 \mathrm{mg} / \mathrm{mL}$ ) was diluted to a final concentration of $40 \mu \mathrm{g} / \mathrm{mL}$ in sodium acetate buffer (10 mM; pH 5.0) and immobilized to a PEG or a CM5 sensor chip using an amine coupling method. ${ }^{19}$ The Mpro protein was immobilized on the flow cell, and immobilization levels range from 6000 to 8000 RUs. Test samples were dissolved in phosphate-buffered saline (PBS; $20 \mathrm{mM}$ ) containing $3 \%$ DMSO to reach various concentrations ranging from 0.3 to $600 \mu \mathrm{M}$ and then eluded with running buffer at a flow rate of $30-100 \mu \mathrm{L} / \mathrm{min}$ for $30-60 \mathrm{~s}$. Running buffer was then kept running for $120 \mathrm{~s}$ to dissociate the test sample from the protein, and solvent correction cycles consisting of eight correction points $(2.5-3.8 \%$ DMSO) was performed. The SPR analysis was performed by fitting the raw data (Supporting Information) into simulated curves with a 1:1 binding model using the BIAcore T200 evaluation software.

Molecular Docking. The structures of test compounds in *mol2 format were obtained from the Traditional Chinese Medicine Systems Pharmacology Database and Analysis Platform (TCMSP) database (https://tcmsp-w.com/tcmsp.php) and the PubChem Compound database (https://www.ncbi.nlm.nih.gov/pccompound) and then converted to the *pdbqt format. The 3D structure of the SARSCoV-2 Mpro protein was obtained from the protein database (https://www.rcsb.org) and converted to its *pdbqt format. Water removal and hydrogenation on the protein were performed using the PyMol software. The docking spatial coordinates were optimized by the AutoDock software, and the Biovia Discovery Studio Visualizer 4.5 was used to analyze and visualize the interactions between test compounds and the enzyme protein.

\section{RESULTS}

Ellagitannins PA and EA Bind to SARS-CoV-2 Mpro and Inhibit Its Activity. Hydrolyzable ellagitannins including PA and EA showed inhibitory effects on the enzyme activity of
SARS-CoV-2 Mpro. PA and EA at concentrations of 2, 10, and $50 \mu \mathrm{M}$ reduced the enzyme activity in a concentrationdependent manner by 2,59 , and $100 \%$ and 3,28 , and $57 \%$, respectively (Figure 2A,B). To validate PA's and EA's SARSCoV-2 Mpro inhibitory activities, their binding affinities to the Mpro protein were assessed by an SPR assay. Optimal SPR conditions were developed with regard to types of sensor chips, binding time, dissociate time, flow rate, and regeneration buffer (Table 1). Using an instrumental condition developed for

Table 1. Experimental Conditions of the SPR Assay Measuring the Binding Capacity between Ellagitannins PA and EA, Gallotannins TA and PGG, Tannin Metabolites UB and PGY, and the SARS-CoV-2 Mpro Protein

\begin{tabular}{llcll}
$\begin{array}{c}\text { instrumentation } \\
\text { parameter }\end{array}$ & $\begin{array}{c}\text { condition 1 } \\
\text { (ellagitannins) }\end{array}$ & $\begin{array}{c}\text { condition 2 } \\
\text { (gallotannins) }\end{array}$ & $\begin{array}{c}\text { condition } \\
3(\mathrm{UB})\end{array}$ & $\begin{array}{c}\text { condition } \\
4(\mathrm{PYG})\end{array}$ \\
$\begin{array}{l}\text { sensor chip } \\
\text { binding time (s) }\end{array}$ & PEG & PEG & PEG & CM5 \\
$\begin{array}{c}\text { dissociate time } \\
(\mathrm{s})\end{array}$ & 120 & 30 & 30 & 60 \\
$\begin{array}{c}\text { flow rate }(\mu \mathrm{L} / \\
\text { min) }\end{array}$ & 100 & 120 & 120 & 120 \\
$\begin{array}{c}\text { regeneration } \\
\text { buffer }\end{array}$ & glycine 2.0 & 30 & 30 & 100 \\
\hline
\end{tabular}

ellagitannins (condition 1), PA (at concentrations of 150, 75, 38, and $19 \mu \mathrm{M}$ ) and EA (at concentrations of 19, 5, 2, and 1 $\mu \mathrm{M})$ were able to directly bind to the SARS-CoV-2 Mpro protein, resulting in different response units (RUs) in a concentration-dependent manner (Figure 2C,D). BIACore simulation of the SPR raw spectra (Supporting Information) provided the corresponding association constant $\left(K_{\mathrm{a}}\right)$, dissociation constant $\left(K_{\mathrm{d}}\right)$, and affinity values $\left(K_{\mathrm{D}}\right)$. PA and EA had tight binding affinity to the SARS-CoV-2 Mpro protein with $K_{\mathrm{D}}$ values of $6.8 \times 10^{-6}$ and $2.7 \times 10^{-6} \mathrm{M}$, respectively (Table 2).

Gallotannins Bind to SARS-CoV-2 Mpro and Inhibit Its Activity. Gallotannins showed a similar trend of inhibitory 
Table 2. Binding Parameters Including $K_{\mathrm{a}}, K_{\mathrm{d}}$, and $K_{\mathrm{D}}$ between Ellagitannins (PA and EA), Gallotannins (TA and PGG), Tannin Metabolites (UB and PYG), and SARS-CoV2 Mpro Protein Generated from the SPR Experiments Using Their Respective Conditions 1-4

\begin{tabular}{ccccc} 
ligand & & \multicolumn{3}{c}{ binding parameter } \\
\cline { 1 - 2 } \cline { 5 - 5 } ellagitannins & & $K_{\mathrm{a}}(1 / \mathrm{Ms})$ & $K_{\mathrm{d}}(1 / \mathrm{s})$ & $K_{\mathrm{D}}(\mathrm{M})$ \\
PA & & 697.3 & 0.0047 & $6.84 \times 10^{-6}$ \\
EA & & 4755.2 & 0.0130 & $2.74 \times 10^{-6}$ \\
gallotannins & & $K_{\mathrm{a}}(1 / \mathrm{Ms})$ & $K_{\mathrm{d}}(1 / \mathrm{s})$ & $K_{\mathrm{D}}(\mathrm{M})$ \\
TA & & 6309.0 & 0.0071 & $1.13 \times 10^{-6}$ \\
PGG & & 3991.0 & 0.0173 & $4.33 \times 10^{-6}$ \\
GA & 2657 & 0.0031 & $1.18 \times 10^{-6}$ \\
metabolites & & $K_{\mathrm{a}}(1 / \mathrm{Ms})$ & $K_{\mathrm{d}}(1 / \mathrm{s})$ & $K_{\mathrm{D}}(\mathrm{M})$ \\
UB & 1874.0 & 0.0988 & $5.27 \times 10^{-5}$ \\
PYG & 661.8 & 0.0024 & $3.59 \times 10^{-6}$
\end{tabular}

effects on the activity of SARS-CoV-2 Mpro. Larger gallotannins including TA and PGG (at concentrations of 2, 10 , and $50 \mu \mathrm{M})$ showed strong enzyme inhibitory activity in a concentration-dependent manner with inhibition rates of 13 , 73 , and $100 \%$ and 14,73 , and $100 \%$, respectively, while the smaller gallotannins, GA and GLA, showed weaker inhibitory effects with inhibition rates of $7-37$ and $0-7 \%$, respectively (Figure 3A). The inhibitory effects of TA and PGG on SARSCoV-2 Mpro were supported by data from the SPR experiments with optimized instrumental parameters suitable for detecting the binding affinities of gallotannins (condition 2; Table 1). TA and PGG had a strong binding capacity with high RUs (up to 643 and 1186, respectively) in their SPR sensorgrams (Figure 3B) with $K_{\mathrm{a}}, K_{\mathrm{d}}$, and $K_{\mathrm{D}}$ values of 6309.0, 0.0071, and $1.1 \times 10^{-6} \mathrm{M}$ and 3991.0, 0.0173, and 4.3 $\times 10^{-6} \mathrm{M}$, respectively (Table 2 ).
Gut Microbial Metabolites of Hydrolyzable Tannins have Weaker Inhibitory Effects on SARS-CoV-2 Mpro. Ellagitannins' and gallotannins' gut microbial metabolites, namely, UA, UA's phase II conjugate (mUA), ${ }^{20}$ and UB and PYG, respectively, were also evaluated for their inhibitory effects on SARS-CoV-2 Mpro activity at physiologically relevant concentrations (up to $50 \mu \mathrm{M}$ ). ${ }^{21}$ Compared to their parent compounds, these metabolites showed weaker inhibitory effects, in which UA, mUA, and UB (at concentrations of $2-50 \mu \mathrm{M})$ inhibited the enzyme activity by $0-26,13-21$, and 18-30\%, respectively, while PYG had comparable inhibition rates of $22-38 \%$ (Figure 4A). Additionally, the SPR instrumental parameters were optimized to measure the binding affinity between these metabolites and SARS-CoV-2 Mpro protein (conditions 3 and 4; Table 1). Ellagitannins' metabolites including UA and its phase II conjugate, mUA, had undetectable binding capacity as shown in their SPR sensorgrams (Supporting Information), while UB had a weak binding capacity with low SPR responses $(\mathrm{RU}<10)$ (Figure 4B). The binding parameters including $K_{a}, K_{d}$, and $K_{D}$ of UB and PYG were obtained from their SPR sensorgrams and are summarized in Table 2.

Notably, two dietary botanical extracts, namely, pomegranate fruit extract (PE; commercially available as Pomella; from Verdure Sciences; Noblesville, IN, USA and red maple leaves extract (MLE; commercially available as Maplifa), whose phytochemical contents were standardized based on their major hydrolyzable tannins (c.a. $33 \%$ of PA and $41 \%$ of GA, respectively), ${ }^{16,18,22}$ showed promising inhibitory effects against SARS-CoV-2 Mpro at 2, 10, and $50 \mu \mathrm{g} / \mathrm{mL}$ with inhibition rates of 29,53 , and $94 \%$ and 8,18 , and $61 \%$, respectively (Figure 5). Additionally, quercetin, a common dietary flavonoid that has been identified as an inhibitor of SARS-CoV-2 Mpro by several in silico studies, ${ }^{23,24}$ was included as a positive control and showed moderate inhibitory
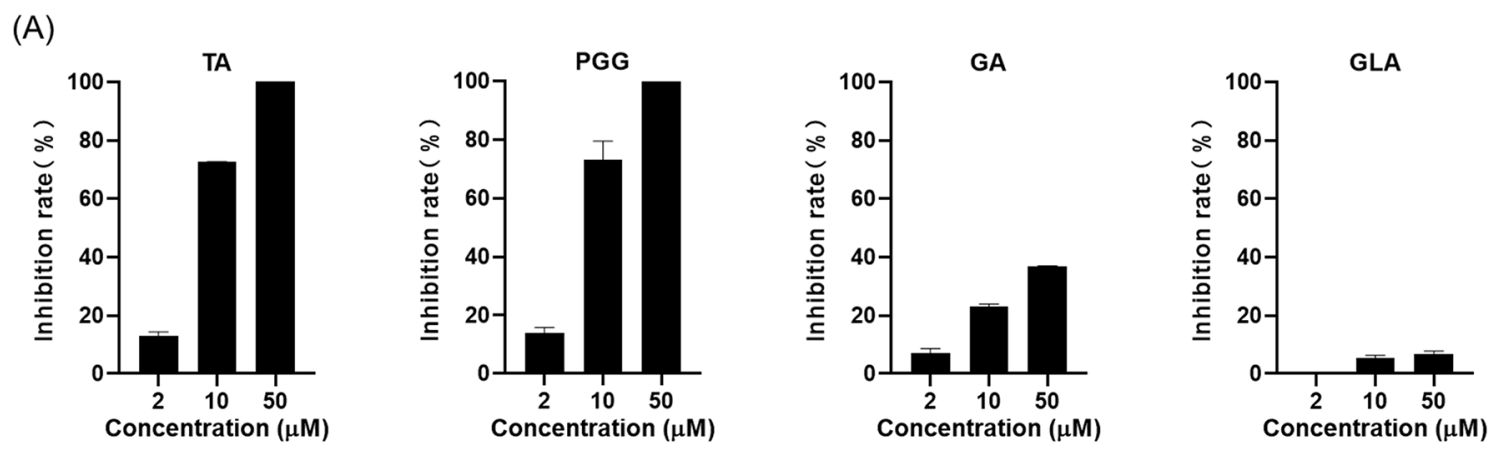

(B)
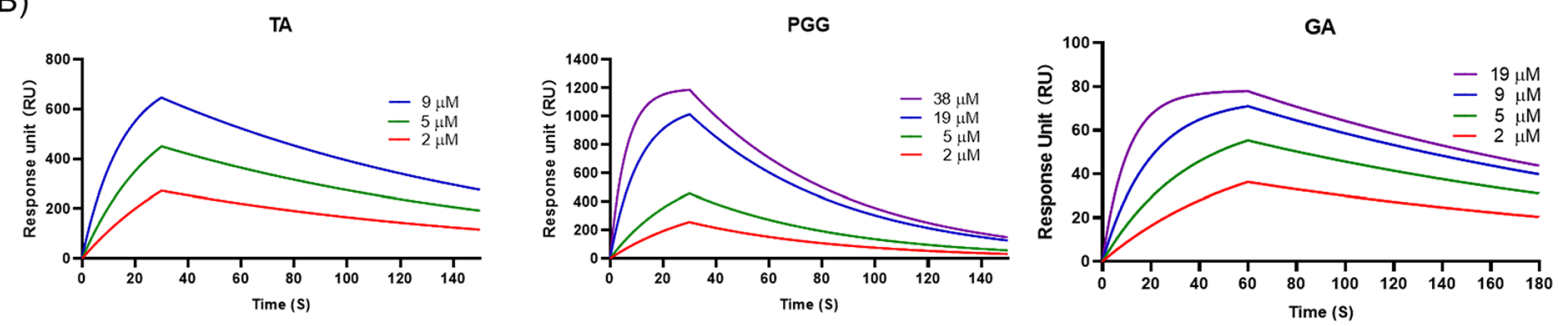

Figure 3. Inhibitory effects of gallotannins, TA, PGG, GA, and GLA (at concentrations of 2, 10, and $50 \mu \mathrm{M}$ ) on SARS-CoV-2 Mpro enzyme activity by an MBP-tagged SARS-CoV-2 Mpro protease assay kit (A). SPR sensorgrams of TA, PGG, and GA characterizing their direct binding capacity with the SARS-CoV-2 Mpro protein (B). 
(A)

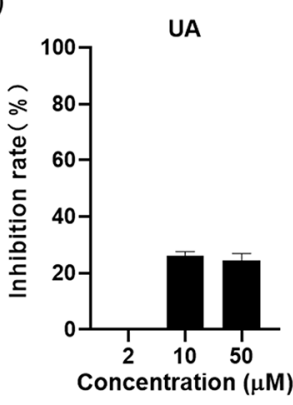

(B)

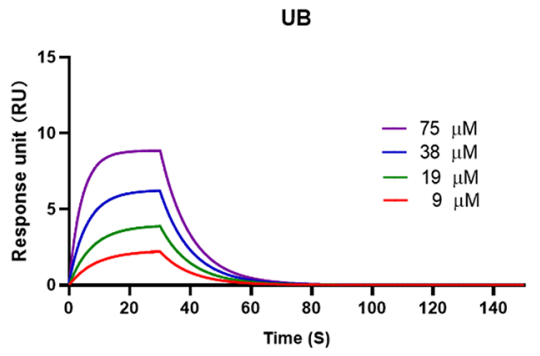

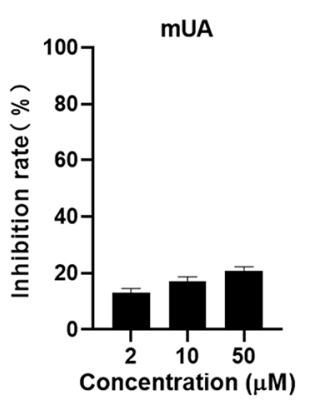
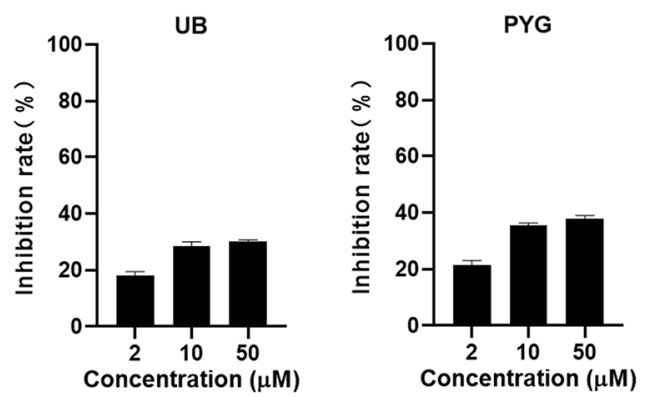

Figure 4. Inhibitory effects of hydrolyzable tannins' gut microbial metabolites, namely, UA, mUA, UA, and PYG (at concentrations of 2, 10, and 50 $\mu \mathrm{M}$ ) on SARS-CoV-2 Mpro enzyme activity by an MBP-tagged SARS-CoV-2 Mpro protease assay kit (A). SPR sensorgrams of UB and PYG characterizing their direct binding capacity with SARS-CoV-2 Mpro protein (B).

(A)

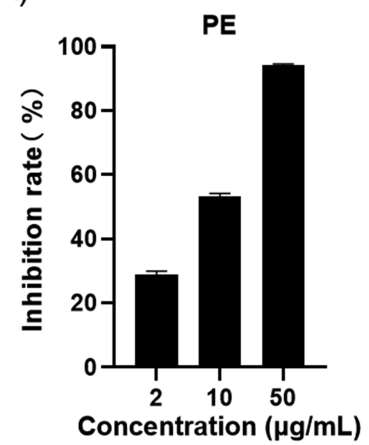

(B)

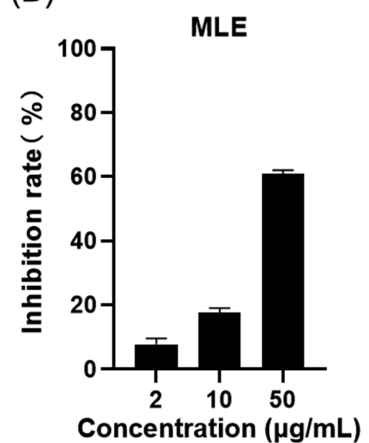

Figure 5. Inhibitory effects of ellagitannins enriched pomegranate extract (PE; Pomella) (A) and gallotannins enriched red maple leaves extract (MLE; Maplifa) (B) (at concentrations of 2, 10, and $50 \mu \mathrm{g}$ / $\mathrm{mL}$ ) on SARS-CoV-2 Mpro enzyme activity by an MBP-tagged SARS-CoV-2 Mpro protease assay kit.

effects with inhibition rates of $3-63 \%$ at $2-50 \mu \mathrm{M}$, respectively (Supporting Information). GC376, a synthetic compound used as a positive control for the SARS-CoV-2 Mpro assay kit, showed potent inhibitory effects with inhibition rates of 27,85 , and $90 \%$ at $0.2,0.8$, and $20 \mu \mathrm{M}$, respectively (Supporting Information).

Furthermore, quercetin and GLA, which were predicted to show inhibition on SARS-CoV-2 Mpro based on several in silico studies, ${ }^{11,24-26}$ were evaluated for their binding capacity to the enzyme protein with the SPR assay. Quercetin had higher RUs in the SPR sensorgrams ranging up to 103, while GLA showed weaker binding capacity with lower RUs up to 30 (Figure 6). This was supported by their binding parameters as quercetin had a lower $K_{\mathrm{D}}\left(6.1 \times 10^{-6} \mathrm{M}\right)$ as compared to GLA's $\left(1.1 \times 10^{-5} \mathrm{M}\right)$ (Table 3). Data obtained from the biochemical inhibition assay and the binding affinity measurements are crucial for providing useful information to guide computational based investigations on the interactions between the SARS-CoV-2 Mpro enzyme and its inhibitors. Thus, quercetin and GLA were used as probes to optimize the

\section{Quercetin}

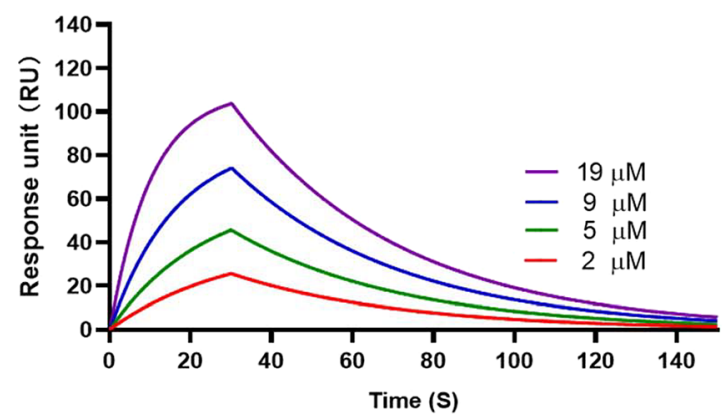

GLA

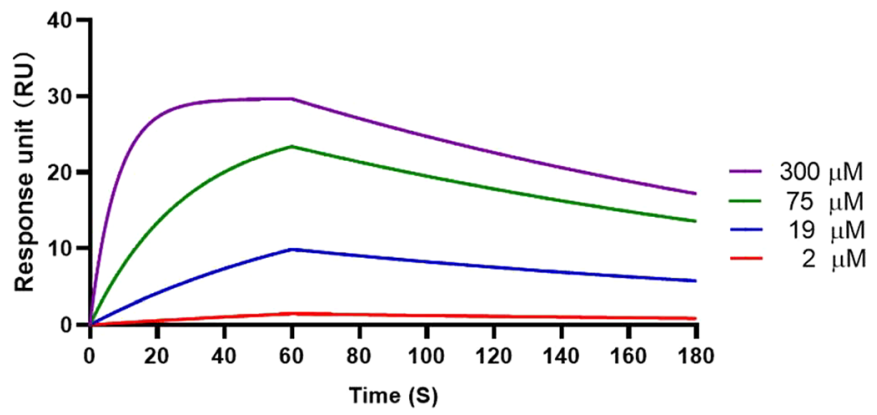

Figure 6. SPR sensorgrams of known natural SARS-CoV-2 Mpro inhibitors including quercetin and GLA characterizing their direct binding capacity with SARS-CoV-2 Mpro protein. 
Table 3. SPR Binding Parameters Including $K_{\mathrm{a}}, K_{\mathrm{d}}$, and $K_{\mathrm{D}}$ of Quercetin and GLA with the SARS-CoV-2 Mpro Protein

\begin{tabular}{cccc} 
binding parameter & $K_{\mathrm{a}}(1 / \mathrm{Ms})$ & $K_{\mathrm{d}}(1 / \mathrm{s})$ & $K_{\mathrm{D}}(\mathrm{M})$ \\
quercetin & 4019.0 & 0.0244 & $6.08 \times 10^{-6}$ \\
GLA & 400.6 & 0.0045 & $1.14 \times 10^{-5}$ \\
\hline
\end{tabular}

computational method to explore the interactions of hydrolyzable tannin-based ligands and SARS-CoV-2 Mpro protein. Quercetin and GLA could fit into the binding pocket of the Mpro protein to form a ligand-protein complex with the help of several hydrogen bonding and hydrophobic interactions (Figure 7). Their predicted binding parameters including the free binding energies, numbers of hydrogen bonds, and amino acid residues involved in the formation of hydrogen bonds are listed in Table 4.

Dietary Hydrolyzable Tannins and Their Metabolites Interact with SARS-CoV-2 Mpro Protein. Next, the interactions between the SARS-CoV-2 Mpro enzyme and its inhibitors were delineated by computational-based experiments. It was predicted that gallotannins including TA, PGG, and GA had strong binding affinity to the Mpro protein with a free binding energy of $-8.3,-8.3$, and $-7.9 \mathrm{kcal} / \mathrm{mol}$, respectively (Table 5). Ellagitannins, PA and EA, also had low free binding energies $(-8.1$ and $-7.5 \mathrm{kcal} / \mathrm{mol}$, respectively). These predictions agree with data obtained from the SPR binding assays. Gut microbial metabolites of the hydrolyzable tannins including mUA, UA, UB, and PYG had higher free binding energies ranging from -6.8 to $-4.7 \mathrm{kcal} / \mathrm{mol}$, which were correlated to the extent of their interactions with the protein amino acid residues. For instance, hydrolyzable tannins
Table 4. Molecular Interactions Including Free Binding Energy, Numbers of Hydrogen Bonds, and Amino Acid Residues Forming H-Bond with their Length between Ligands Quercetin or GLA and SARS-CoV-2 Mpro Protein Predicted by Computational Docking

\begin{tabular}{lccc} 
Ligand & $\begin{array}{c}\text { Free } \\
\text { binding } \\
\text { energy } \\
\text { (kcal/mol) }\end{array}$ & H-bonds \# & $\begin{array}{c}\text { Amino acid residues forming } \mathrm{H}- \\
\text { bond with their length in } \AA\end{array}$ \\
Quercetin & -7.5 & 6 & $\begin{array}{c}\text { Gly143 (2.39), Cys145(2.29), } \\
\text { Cys145(2.29), Cys145(4.69), } \\
\text { Glu166(3.31), Glu166(2.18) }\end{array}$ \\
GLA & -5.1 & 3 & $\begin{array}{c}\text { Leu141 (2.52), Gly143 (2.12), } \\
\text { Glu166 (2.03) }\end{array}$ \\
\hline
\end{tabular}

formed more numbers of hydrogen bond (10-17) with the amino acids of protein as compared to their metabolites (3-6 hydrogen bonds) (Table 5). The binding site of representative tannins, PA and TA, and their respective metabolite, UB and PYG, on the Mpro protein are shown in Figure 8 (A, C, E, and $G$, respectively), and the major molecular forces that formed between the ligands and Mpro protein are illustrated in Figure 8 ( $\mathrm{B}, \mathrm{D}, \mathrm{F}$, and $\mathrm{H}$, respectively). For instance, PA and TA occupied the binding site of the enzyme protein to form several molecular bonds including conventional and carbon hydrogen bonds, such as hydrogen bonds that formed between amino acid residues and the hydroxyl groups on the hexahydroxydiphenoyl moiety of PA (Figure $8 \mathrm{~B}$ ) or the carbonyl group on the galloyl moiety of TA (Figure $8 \mathrm{D}$ ) as well as the $\pi$-alkyl bond that formed between amino acids and the benzyl ring of the galloyl groups on PA or TA (Figure 8B,D). Meanwhile,
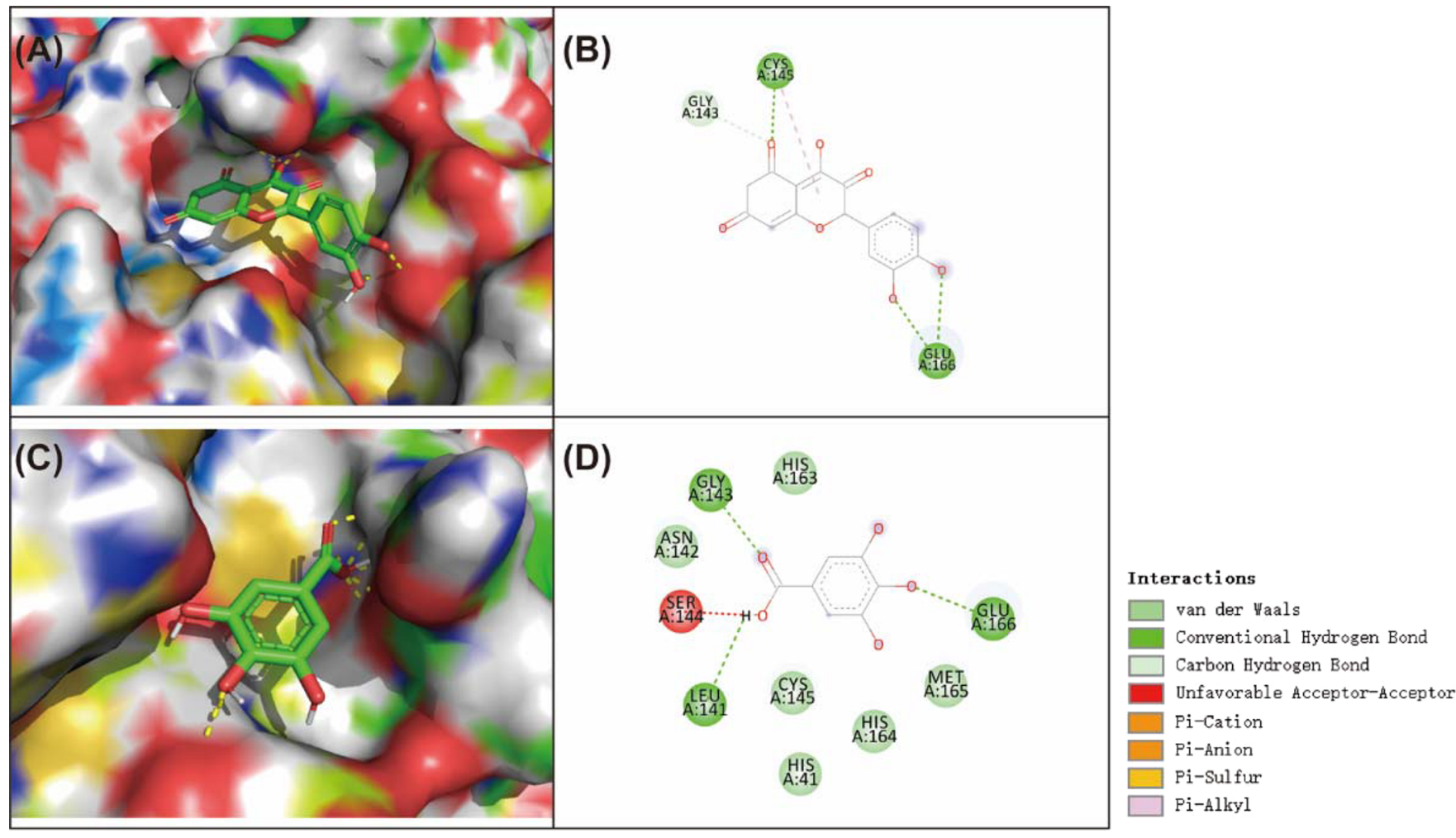

Figure 7. Molecular interactions between two known natural SARS-CoV-2 Mpro inhibitors including quercetin and GLA and the Mpro protein illustrated by $3 \mathrm{D}$ and $2 \mathrm{D}$ images (A-D, respectively). The ligand surface was created based on partial charge, and the protein surface was arranged by the secondary structures for the $3 \mathrm{D}$ interactions. Molecular forces that formed between the moieties of different ligands and protein amino acid residues are presented in the $2 \mathrm{D}$ interactions. 
Table 5. Molecular Interactions Including Free Binding Energy, Numbers of Hydrogen Bonds, and Amino Acid Residues Forming H-Bond with their Length between Ellagitannins, Gallotannins, and their Metabolites and SARS-CoV-2 Mpro Protein Predicted by Computational Docking

\begin{tabular}{|c|c|c|c|}
\hline ligand & $\begin{array}{l}\text { free binding } \\
\text { energy (kcal/ } \\
\text { mol) }\end{array}$ & H-bonds \# & amino acid residues forming an H-bond with their length in $\AA$ \\
\hline PGG & -8.3 & 17 & $\begin{array}{l}\text { Thr190 (2.56), Leu141 (2.83, 2.45), Glu166 (2.40), Phe140 (2.41), His163 (2.62, 2.63), Asn142 (2.43, 3.02, 3.60), } \\
\text { Ser144 (3.89), Thr25 (2.31, 2.63), Gly143 (2.88), Thr26 (2.37), Cys145 (2.44), His41 (2.41) }\end{array}$ \\
\hline TA & -8.3 & 15 & $\begin{array}{l}\text { Asn119 (5.96), Gln189 (2.28, 2.44, 3.43), Ser46 (2.19, 2.80, 2.96, 2.43, 2.86), His } 164 \text { (2.55), Met165 (2.78), Pro168 } \\
\quad(2.83) \text {, Glu166 (2.83, 2.13, 2.60) }\end{array}$ \\
\hline PA & -8.1 & 9 & Glu166 (2.16, 2.68), Ser144 (2.57), Cys145 (2.44), Thr26 (3.02), His163 (2.50, 2.99), Gly143 (2.41), Gln189 (3.42) \\
\hline GA & -7.9 & 10 & Ser46 (2.05, 2.39), Thr24 (2.93), Thr26 (2.37, 3.76), Gly143 (1.91), Glu166 (2.45, 2.06), His163 (2.84), Leu141 (2.66) \\
\hline EA & -7.5 & 8 & Glu166 (2.78), Ser144 (2.50), Gly143 (2.63), Cys 145 (2.87), Thr26 (2.33), His41 (2.64, 2.63), Asn142 (2.82) \\
\hline mUA & -6.8 & 6 & Glu166 (2.76), Ser144 (2.52, 2.52), Cys145 (2.46), Gly143 (2.20), His41 (2.73) \\
\hline UA & -6.8 & 5 & Glu166 (1.90), Ser144 (2.17, 2.73), Gly143 (2.61), Cys145 (2.63) \\
\hline UB & -6.5 & 5 & Cys145 (2.60), Gly143 (2.61), Ser144 (2.20, 2.77), Glu166 (2.96) \\
\hline PYG & -4.7 & 3 & Thr24 (2.16), Thr25 (2.28), Cys22 (2.88) \\
\hline
\end{tabular}

tannin metabolites, UB and PYG, loosely fitted in the binding cavity, forming less numbers of hydrogen bonds at their hydroxyl group (Figure 8F,H).

\section{DISCUSSION}

In vitro bioassays, including several commercially available anti-SARS-CoV2 kits, were recently developed to evaluate the biological effects of possible SARS-CoV-2 Mpro inhibitors, and computational experiments may complement these results. A series of ellagitannins, including pedunculagin, tercatain, and castalin, were reported to bind to the catalytic dyad region of the Mpro protein in molecular docking experiments, but their inhibitory effects were not examined by biochemical based assays. ${ }^{13}$ In another study using a cell-based model and biochemical assay, ellagitannins, including chebulagic acid and PA, were reported to reduce virus-induced plaque formation in a transfected monkey kidney epithelial cell (Vero-E6) monolayer and inhibit the enzymatic activity of Mpro in an allosteric manner. ${ }^{27}$ However, bioassays with virus-transfected cells are highly regulated and can only be conducted in appropriate physical containment facilities, such as biosafety level 3 and 4 (BSL-3 and -4) laboratories, ${ }^{28}$ which limit the feasibility of these assay for biological evaluations. In the present study, we used a cell-free fluorescent assay to evaluate the inhibitory activity of dietary hydrolyzable tannins, including ellagitannins and gallotannins, as well as their gut microbial metabolites, on SARS-CoV-2 Mpro. Some preliminary structure-activity relationships (SAR) are observed from the enzyme inhibition assay. It seemed that the inhibitory effects of tannins and their metabolites on the Mpro enzyme are influenced by their numbers of hydroxyl group $(\mathrm{s})(-\mathrm{OH})$ on the aromatic ring(s). TA $(25-\mathrm{OH}), \mathrm{PA}(16-\mathrm{OH}), \mathrm{TA}$, and PGG $(15-\mathrm{OH})$ showed the most potent Mpro inhibition activity as compared to their structural unit (EA with $4-\mathrm{OH}$; GLA with $3-\mathrm{OH}$ ) and their metabolites (urolithins with up to $2-\mathrm{OH}$; PYG with $3-\mathrm{OH}$ ). However, this SAR is not applicable to the comparison among the urolithins, where UB ( $1-\mathrm{OH})$ had higher inhibition than UA $(2-\mathrm{OH})$. It is also noted that tannins, PA, TA, and PGG at higher concentrations (10 and $50 \mu \mathrm{M}$ ) showed promising inhibition (59-100\% inhibition rate) but only exerted weak inhibition at a lower concentration ( $2 \mu \mathrm{M}$; inhibition rates of $2-14 \%)$. This low potency suggests that these tannins may not exert inhibitory effects at physiologically relevant levels, and thus they are not druggable candidates as SARS-CoV-2 Mpro inhibitors. ${ }^{29,30}$
However, given that ellagitannins and gallotannins can be converted by gut microflora to produce relatively more bioavailable metabolites including urolithins and PYG, ${ }^{31-33}$ we also evaluated the inhibitory effects of these metabolites. Notably, the concentrations $(2-50 \mu \mathrm{M})$ of the urolithin metabolites tested in the Mpro inhibition assay are at physiological relevant levels, which are detectable in human colon tissues after consumption of hydrolyzable tannin-rich foods according to previously reported clinical studies. ${ }^{21}$ The majority of these gut microbial metabolites (i.e., UA) did not show potent inhibition against SARS-CoV-2 Mpro (Figure 4A) nor had tight binding capacity with the Mpro protein (Supporting Information). Similarly, UA's phase II conjugate, mUA, showed weak inhibition on the Mpro activity. However, one of the metabolites, PYG, displayed concentration-dependent mannered inhibition with a relatively effective Mpro inhibition rate of $20 \%$ at the lowest test concentration $(2 \mu \mathrm{M})$, which was more pronounced than its parent compounds at the same concentration $(2 \mu \mathrm{M}$; with lower inhibition rates ranging from 0 to $14 \%$ ) (Figure 4A). Although these hydrolyzable tannins showed inhibitory effects on SARS-CoV-2 Mpro in the in vitro assay, it is critical to clarify that these biological effects do not suggest that they would be viable dietary agents for the development of SARS-CoV-2 Mpro inhibitors due to their poor bioavailability. ${ }^{31,32}$ Furthermore, it is possible that the observed in vitro inhibitory effects of the hydrolyzable tannins may be partially attributed to their ability to alter the environment $\mathrm{pH}$ and precipitate enzyme proteins, which may result in the denaturation of the Mpro protein, in the assay reaction system. Therefore, further research efforts to study the bioactive and bioavailable gut microbial metabolites of these tannins as druggable leading compounds may hold greater promise than their parent compounds. Nevertheless, the current data obtained from these in vitro assays provide useful information for the potential development of hydrolyzable tannin-based anti-virus agents for industrial applications.

Apart from hydrolyzable tannins, it is possible that several other types of dietary polyphenols may have potential biological effects on SARS-CoV-2 Mpro. Given that the chemical structures of dietary polyphenols and their gut microbial metabolites are very diverse, these different chemical structures may impart distinct inhibitory effects on SARS-CoV2 Mpro activity. For instance, we found that a different type of dietary polyphenol, namely, the isoflavone, daidzein, and its gut microbial metabolite, equol, only showed weak anti-SARS- 

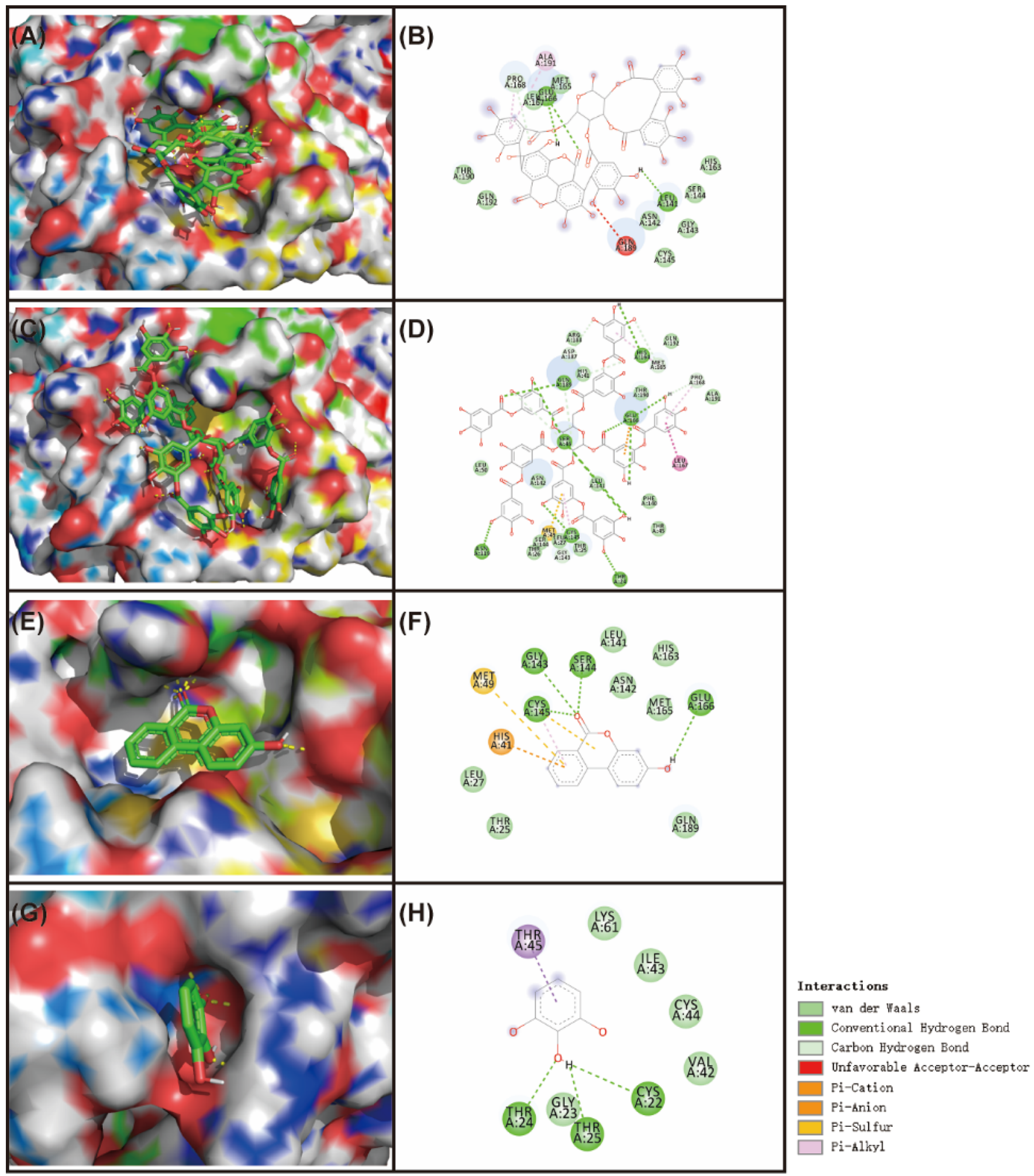

Figure 8. Molecular interactions between the Mpro protein and its representative ligands including ellagitannin PA (A, B), gallotannin (TA; C, D), and their metabolites, UB (E, F) and PYG $(G, H)$, illustrated by $3 D$ and $2 \mathrm{D}$ images, respectively. The ligand surface was created based on partial charge, and the protein surface was arranged by the secondary structures for the $3 \mathrm{D}$ interactions. Molecular forces that formed between the moieties of different ligands and protein amino acid residues are presented in the $2 \mathrm{D}$ interactions.

CoV-2-Mpro effects. At a concentration of $50 \mu \mathrm{M}$, daidzein's inhibitory effect was negligible, whereas equol's inhibition rate was marginally higher (18.5\%) (Supporting Information). This trend was similar to the observation from our previously reported study showing that equol was more active than daidzein in cell-based neuroprotection models. ${ }^{34}$ However, a broader range of dietary polyphenols and their bioavailable metabolites should be included in the further studies on the anti-SARS-CoV-2-Mpro activity for a better understanding of 
dietary polyphenols' role in the potential management and treatment of COVID-19.

The biological assay that evaluated inhibition capacities of tannins and their metabolites were supported by data from the SPR experiments, which were utilized to measure the direct binding affinities with SARS-CoV-2 Mpro. Tannin metabolites PYG and UB had distinct SPR binding characteristics where PYG had higher binding signals compared with UB (Figure $4 \mathrm{~B})$. In addition, the $K_{\mathrm{D}}$ value $\left(3.6 \times 10^{-6} \mathrm{M}\right)$ of PYG is comparable to that of the parent tannins (Table 2). Therefore, it is possible that PYG rather than UB exerted inhibitory effects on SARS-CoV-2 Mpro via the direct binding to the enzyme protein. This data is not fully in agreement with results from the computational study where both PYG and UB showed considerable binding capacity to the Mpro protein (Figure 5). Another discrepancy is that UA was predicted to be able to bind to the Mpro protein by the docking experiments (Table 5) but the biochemical inhibition assay and the SPR study showed that UA did not exert anti-SARS-CoV-2 Mpro effects in a concentration-dependent manner nor directly bind to the Mpro protein (Supporting Information). These discrepancies indicate that it is imperative to validate computational predictions with experimental biochemical and biophysical assays.

In addition to the SPR technique, several biophysical-based binding assays, such as isothermal titration calorimetry (ITC), homogeneous time-resolved fluorescence, and saturation transfer differentiation-based nuclear magnetic resonance, can be used to measure the binding affinity of small molecules and target proteins. However, we considered several factors when selecting the optimal assay for the current project. For instance, binding assays (i.e., fluorescent tag or isotope-labeled assays) that require multiple-step preparation are timeconsuming and labor-intensive and therefore were excluded from the current study. In addition, binding assays that require working with large amounts of protein, such as the ITC model, were not feasible for our study due to the limited availability of the 3CL protease enzyme. Herein, we selected the SPR tool, which is a label-free and sensitive biophysical assay, to investigate the binding profile of our test compounds. SPR is a powerful tool in the drug discovery field for target validation as it not only provides accurate binding characteristics but also possesses several advantages including less protein consumption, simple sample preparation, and relatively quick turnaround time (less than $1 \mathrm{~h}$ running time in our experiments), which made it the best assay of choice in the current study. To our knowledge, the present work is the first study utilizing the SPR technique to investigate the anti-SARS-CoV-2 Mpro activity of natural products. ${ }^{35}$ A critical factor for using the SPR technique to measure accurate binding parameters is to optimize its instrumental configurations to achieve optimal methods for specific ligands and proteins. As summarized in Table 1, we optimized the SPR measurement conditions, including types of sensor chips (PEG vs CM5), binding and dissociate time, flow rate, and regeneration buffers, for different analytes. This adjustment was necessary as the structures and sizes of the test compounds vary significantly, affecting their binding patterns. For instance, the PEG sensor chip was suitable for detecting the binding parameters of the large gallotannin molecules but not ideal for the measurement of their metabolite, PYG. This was since PYG was not only able to bind to the Mpro protein but also had significant binding to the surface of the PEG-coated sensor chip. This may have led to the aggregation of PYG on the surface of PEG chip resulting in high background RU signals, which is considered as interfered binding signals and termed as reference signals. ${ }^{36}$ The reference signal can be calculated as the ratio of reference binding RUs over the binding level RUs (Supporting Information), and a reference signal greater than $35 \%$ is often considered as significantly interfered. ${ }^{36,37}$ In our case, a large reference signal (64\%) was observed when PYG was analyzed with the PEG sensor chip. To address this issue, we used a CM5 sensor chip, which generated less than $10 \%$ reference binding signal. Thus, it is critical to develop analytical methods with suitable instrumental conditions to study the binding characteristics of SARS-CoV-2 Mpro inhibitors. Moreover, there are some limitations in using SPR-based binding assays to study the mechanism of Mpro inhibitors. For instance, data from the SPR experiments may not be sufficient to differentiate the type of inhibition on the enzyme. In our case, large hydrolyzable tannins including PA, TA, and PGG had highly positive SPR results (see their binding parameters in Table 2) and strong inhibition rates (Figures $2 \mathrm{~A}$ and $3 \mathrm{~A}$ ). However, these observations may be attributed to the proteinprecipitating effects of these large tannins, which can ubiquitously interact with proteins and form the tanninprotein complexes, resulting in loss of enzyme functions. ${ }^{38,39}$ In addition, it is not clear whether these tannins bind to the catalytic domain, as predicted by the molecular docking experiment $^{13}$ or the allosteric site on the enzyme protein as reported in studies using in vitro models. ${ }^{27}$ These shortcomings may be overcome by utilizing complementary experimental methods, including competitive binding assays and/or X-ray crystal work.

Two commercially available dietary botanical extracts, namely, PE and MLE, which are chemically standardized to their major ellagitannins (PA and EA) and gallotannin (GA), respectively, also exerted promising anti-SARS-CoV-2 Mpro activity (Figure 5). This is in agreement with previously reported studies showing that pomegranate peel extracts have anti-virus effects ${ }^{40-42}$ and, therefore, can be used as anti-viral materials for industrial food applications such as food packaging materials. ${ }^{43}$ Although PE and MLE and their major constituent hydrolysable tannins may not be suitable drug candidates as SARS-CoV-2 Mpro inhibitors, they show promise and may be explored as potential anti-viral materials for food industry applications but further studies would be required to confirm this.

In summary, dietary hydrolyzable tannins, including ellagitannin (PA) and gallotannins (TA and PGG), exerted promising inhibitory effects on SARS-CoV-2 Mpro activity at high concentrations $(10$ and $50 \mu \mathrm{M})$. Smaller tannins, including EA, GA, and GLA, as well as their gut metabolites, urolithins and PYG, only showed mild anti-SARS-CoV-2 Mpro effects. The SPR binding assays revealed that these hydrolyzable tannins and one of the metabolites, PYG, can directly bind to the SARS-CoV-2 Mpro protein, but their druggability seems low. Although data from the biochemical and biophysical binding assays suggested that hydrolyzable tannins may not be effective and bioavailable SARS-CoV-2 Mpro inhibitors, hydrolyzable tannins with anti-viral activity should be explored for other potential applications such as food packaging materials. The present study provides useful insights for the development of natural product-derived molecules for the development of SARS-CoV-2 Mpro inhibitors. 


\section{ASSOCIATED CONTENT}

\section{SI Supporting Information}

The Supporting Information is available free of charge at https://pubs.acs.org/doi/10.1021/acs.jafc.1c03521.

Raw data of the SPR experiments (Figure S1), sensorgrams showing the binding characterization of UA and mUA with the Mpro protein by the SPR experiments (Figure S2), inhibitory effects of quercetin and GC376 on SARS-CoV-2 Mpro enzyme activity (Figure S3), SPR reference binding signals of PYG with SARS-CoV-2 Mpro protein using two sensor chips PEG and CM5 (Table S1), and inhibitory effects of daidzein and equol on SARS-CoV-2 Mpro enzyme activity (Table S2) (PDF)

\section{AUTHOR INFORMATION}

\section{Corresponding Author}

Hang Ma - School of Biotechnology and Health Sciences, Wuyi University, International Healthcare Innovation Institute (Jiangmen), Jiangmen 529020, China; Department of Biomedical and Pharmaceutical Sciences, College of Pharmacy, University of Rhode Island, Kingston, Rhode Island 02881, United States; (1) orcid.org/0000-0001-75656889; Phone: +1 401874 7654; Email: hang_ma@ uri.edu; Fax: +1 4018742181

\section{Authors}

Huifang Li - School of Biotechnology and Health Sciences, Wuyi University, International Healthcare Innovation Institute (Jiangmen), Jiangmen 529020, China; Department of Biomedical and Pharmaceutical Sciences, College of Pharmacy, University of Rhode Island, Kingston, Rhode Island 02881, United States

Feng Xu - Department of Biomedical and Pharmaceutical Sciences, College of Pharmacy, University of Rhode Island, Kingston, Rhode Island 02881, United States; College of Pharmacy, Guizhou University of Traditional Chinese Medicine, Guiyang 550001, China

Chang Liu - Department of Biomedical and Pharmaceutical Sciences, College of Pharmacy, University of Rhode Island, Kingston, Rhode Island 02881, United States

Ang Cai - Department of Biomedical and Pharmaceutical Sciences, College of Pharmacy and Department of Chemistry, University of Rhode Island, Kingston, Rhode Island 02881, United States

Joel A. Dain - Department of Chemistry, University of Rhode Island, Kingston, Rhode Island 02881, United States

Dongli Li - School of Biotechnology and Health Sciences, Wuyi University, International Healthcare Innovation Institute (Jiangmen), Jiangmen 529020, China

Navindra P. Seeram - Department of Biomedical and Pharmaceutical Sciences, College of Pharmacy, University of Rhode Island, Kingston, Rhode Island 02881, United States; (1) orcid.org/0000-0001-7064-2904

Bongsup P. Cho - Department of Biomedical and Pharmaceutical Sciences, College of Pharmacy, University of Rhode Island, Kingston, Rhode Island 02881, United States

Complete contact information is available at:

https://pubs.acs.org/10.1021/acs.jafc.1c03521

\section{Author Contributions}

${ }^{\| H . L . ~ a n d ~ F . X . ~ h a v e ~ e q u a l ~ c o n t r i b u t i o n ~}$

\section{Notes}

The authors declare no competing financial interest.

\section{ACKNOWLEDGMENTS}

Spectrometric data were acquired from instruments located at the University of Rhode Island in the RI-INBRE core facility obtained from grant \#P20GM103430 from the National Center for Research Resources (NCRR), a component of the National Institutes of Health (NIH). H.L. and D.L. were supported by funding from the Department of Education of Guangdong Province (nos. 2017KSYS010 and 2019KZDZX2003) and the Jiangmen Program for Innovative Research Team (no. 2018630100180019806). We thank Robyn Stoller (Application Scientist) from Biacore, Cytiva for their excellent technical support on the SPR experiments.

\section{ABBREVIATIONS}

3CLpro, 3-chymotrypsin-like protease; COVID-19, coronavirus disease 2019; EA, ellagic acid; GA, ginnalin A; GLA, gallic acid; ITC, isothermal titration calorimetry; $K_{a}$ association constant; $K_{\mathrm{d}}$, dissociation constant; $K_{\mathrm{D}}$, equilibrium constant; $\mathrm{MBP}$, maltose binding protein; Mpro, main protease; mUA, methylated urolithin A; PA, punicalagin; PGG, 1,2,3,4,6-penta$O$-galloyl- $\beta$-D-glucose; PYG, pyrogallol; SARS-CoV-2, severe acute respiratory syndrome coronavirus; SPR, surface plasmon resonance; TA, tannic acid; $\mathrm{UA}$, urolithin $\mathrm{A}$; $\mathrm{UB}$, urolithin $\mathrm{B}$

\section{REFERENCES}

(1) Jin, Z.; Du, X.; Xu, Y.; Deng, Y.; Liu, M.; Zhao, Y.; Zhang, B.; Li, X.; Zhang, L.; Peng, C.; Duan, Y.; Yu, J.; Wang, L.; Yang, K.; Liu, F.; Jiang, R.; Yang, X.; You, T.; Liu, X.; Yang, X.; Bai, F.; Liu, H.; Liu, X.; Guddat, L. W.; Xu, W.; Xiao, G.; Qin, C.; Shi, Z.; Jiang, H.; Rao, Z.; Yang, H. Structure of Mpro from SARS-CoV-2 and discovery of its inhibitors. Nature 2020, 582, 289-293.

(2) Mengist, H. M.; Fan, X.; Jin, T. Designing of improved drugs for COVID-19: crystal structure of SARS-CoV-2 main protease Mpro. Signal Transduction Targeted Ther. 2020, 5, 1-2.

(3) Jin, Z.; Zhao, Y.; Sun, Y.; Zhang, B.; Wang, H.; Wu, Y.; Zhu, Y.; Zhu, C.; Hu, T.; Du, X.; Duan, Y.; Yu, J.; Yang, X.; Yang, X.; Yang, K.; Liu, X.; Guddat, L. W.; Xiao, G.; Zhang, L.; Yang, H.; Rao, Z. Structural basis for the inhibition of SARS-CoV-2 main protease by antineoplastic drug carmofur. Nat. Struct. Mol. Biol. 2020, 27, 529532.

(4) Kneller, D. W.; Phillips, G.; O’Neill, H. M.; Jedrzejczak, R.; Stols, L.; Langan, P.; Joachimiak, A.; Coates, L.; Kovalevsky, A. Structural plasticity of SARS-CoV-2 3CL Mpro active site cavity revealed by room temperature X-Ray crystallography. Nat. Commun. 2020, 11, 16.

(5) Qiao, J.; Li, Y. S.; Zeng, R.; Liu, F. L.; Luo, R. H.; Huang, C.; Wang, Y. F.; Zhang, J.; Quan, B.; Shen, C.; Mao, X.; Liu, X.; Sun, W.; Yang, W.; Ni, X.; Wang, K.; Xu, L.; Duan, Z. L.; Zou, Q. C.; Zhang, H. L.; Qu, W.; Long, Y. H. P.; Li, M. H.; Yang, R. C.; Liu, X.; You, J.; Zhou, Y.; Yao, R.; Li, W. P.; Liu, J. M.; Chen, P.; Liu, Y.; Lin, G. F.; Yang, X.; Zou, J.; Li, L.; Hu, Y.; Lu, G. W.; Li, W. M.; Wei, Y. Q.; Zheng, Y. T.; Lei, J.; Yang, S. SARS-CoV-2 $\mathrm{M}^{\text {pro }}$ Inhibitors with antiviral activity in a transgenic mouse model. Science 2021, 371, 1374-1378.

(6) Rut, W.; Groborz, K.; Zhang, L.; Sun, X.; Zmudzinski, M.; Pawlik, B.; Wang, X.; Jochmans, D.; Neyts, J.; Młynarski, W.; Hilgenfeld, R.; Drag, M. SARS-CoV-2 $\mathrm{M}^{\text {pro }}$ inhibitors and activitybased probes for patient-sample imaging. Nat. Chem. Biol. 2021, 17, 222-228.

(7) Ibrahim, M. A. A.; Abdeljawaad, K. A. A.; Abdelrahman, A. H. M.; Hegazy, M. E. F. Natural-like Products as Potential SARS-CoV-2 $\mathrm{M}^{\mathrm{pro}}$ inhibitors: in-silico drug discovery. J. Biomol. Struct. Dyn. 2021, $39,1-5734$ 
(8) Narkhede, R. R.; Pise, A. V.; Cheke, R. S.; Shinde, S. D. Recognition of natural products as potential inhibitors of COVID-19 main protease $\left(\mathrm{M}^{\mathrm{pro}}\right)$ : in-silico evidences. Nat. Prod. Bioprosp. 2020, 10, 297-306.

(9) Adem, Ş.; Eyupoglu, V.; Sarfraz, I.; Rasul, A.; Zahoor, A. F.; Ali, M.; Abdalla, M.; Ibrahim, I. M.; Elfiky, A. A. Caffeic acid derivatives (CAFDs) as inhibitors of SARS-CoV-2: CAFDs-based functional foods as a potential alternative approach to combat COVID-19. Phytomedicine 2021, 85, 153310.

(10) Gogoi, N.; Chowdhury, P.; Goswami, A. K.; Das, A.; Chetia, D.; Gogoi, B. Computational guided identification of a citrus flavonoid as potential inhibitor of SARS-CoV-2 main protease. Mol. Diversity 2021, 25, 1-1759.

(11) Ibrahim, M. A. A.; Mohamed, E. A. R.; Abdelrahman, A. H. M.; Allemailem, K. S.; Moustafa, M. F.; Shawky, A. M.; Mahzari, A.; Hakami, A. R.; Abdeljawaad, K. A. A.; Atia, M. A. M. Rutin and flavone analogs as prospective SARS-CoV-2 main protease inhibitors: in silico drug discovery study. J. Mol. Graphics Modell. 2021, 105, 107904.

(12) Francisco, F. W.; Castro Matos, M. G.; Marinho, E. M.; Marinho, M. M.; Róseo Paula Pessoa Bezerra de Menezes, R.; Sampaio, T. L.; Bandeira, P. N.; Celedonio Fernandes, C. F.; Magno Rodrigues Teixeira, A.; Marinho, E. S.; de Lima-Neto, P.; Silva dos Santos, H. In silico study of the potential interactions of $4^{\prime}$ acetamidechalcones with protein targets in SARS-CoV-2. Biochem. Biophys. Res. Commun. 2021, 537, 71-77.

(13) Khalifa, I.; Zhu, W.; Hamed, H.; Mohammed, H.; Dutta, K.; Li, C.; Li, C. Tannins inhibit SARS-CoV-2 through binding with catalytic dyad residues of 3CL pro : An in silico approach with 19 structural different hydrolysable tannins practical applications. J. Food Biochem. 2020, 44, 13432.

(14) Xu, J.; Yuan, C.; Wang, G.; Luo, J.; Ma, H.; Xu, L.; Mu, Y.; Li, Y.; Seeram, N. P.; Huang, X.; Li, L. Urolithins attenuate LPS-induced neuroinflammation in BV2Microglia via MAPK, Akt, and NF-KB signaling pathways. J. Agric. Food Chem. 2018, 66, 571-580.

(15) Liu, W.; Ma, H.; Frost, L.; Yuan, T.; Dain, J. A.; Seeram, N. P. Pomegranate phenolics inhibit formation of advanced glycation endproducts by scavenging reactive carbonyl species. Food Funct. 2014, 5, 2996-3004.

(16) Yuan, T.; Ma, H.; Liu, W.; Niesen, D. B.; Shah, N.; Crews, R.; Rose, K. N.; Vattem, D. A.; Seeram, N. P. Pomegranate's neuroprotective effects against Alzheimer's disease are mediated by urolithins, its ellagitannin-gut microbial derived metabolites. ACS Chem. Neurosci. 2016, 7, 26-33.

(17) Ma, H.; Yuan, T.; Gonzalez-Sarrías, A.; Li, L.; Edmonds, M. E.; Seeram, N. P. New galloyl derivative from winged sumac (Rhus copallinum) fruit. Nat. Prod. Commun. 2012, 7, 45-46.

(18) Zhang, Y.; Ma, H.; Yuan, T.; Seeram, N. P. Red maple (Acer rubrum) aerial parts as a source of bioactive phenolics. Natu. Prod. Commun. 2015, 10, 1409-1412.

(19) Muñoz, E. M.; Yu, H.; Hallock, J.; Edens, R. E.; Linhardt, R. J. Poly(ethylene glycol)-based biosensor chip to study heparin-protein interactions. Anal. Biochem. 2005, 343, 176-178.

(20) Espín, J. C.; González-Barrio, R.; Cerdá, B.; López-Bote, C.; Rey, A. I.; Tomás-Barberán, F. A. Iberian pig as a model to clarify obscure points in the bioavailability and metabolism of ellagitannins in humans. J. Agric. Food Chem. 2007, 55, 10476-10485.

(21) Nuñez-Sánchez, M. A.; García-Villalba, R.; Monedero-Saiz, T.; García-Talavera, N. v.; Gómez-Sánchez, M. B.; Sánchez-Álvarez, C.; García-Albert, A. M.; Rodríguez-Gil, F. J.; Ruiz-Marín, M.; PastorQuirante, F. A.; Martínez-Díaz, F.; Yáñez-Gascón, M. J.; GonzálezSarrías, A.; Tomás-Barberán, F. A.; Espín, J. C. Targeted metabolic profiling of pomegranate polyphenols and urolithins in plasma, urine and colon tissues from colorectal cancer patients. Mol. Nutr. Food Res. 2014, 58, 1199-1211.

(22) Liu, C.; Xu, Y.; Kirk, R. D.; Li, H.; Li, D.; DaSilva, N. A.; Bertin, M. J.; Seeram, N. P.; Ma, H. Inhibitory effects of skin permeable glucitol-core containing gallotannins from red maple leaves on elastase and their protective effects on human keratinocytes. J. Funct. Foods 2020, 75, 104208.

(23) Majumder, R.; Mandal, M. Screening of plant-based natural compounds as a potential COVID-19 main protease inhibitor: An in silico docking and molecular dynamics simulation approach. J. Biomol. Struct. Dyn. 2020, 39, 1-16.

(24) Derosa, G.; Maffioli, P.; D’Angelo, A.; Di Pierro, F. A role for quercetin in coronavirus disease 2019 (COVID-19). Phytother. Res. 2021, 35, 1230-1236.

(25) Umar, H. I.; Siraj, B.; Ajayi, A.; Jimoh, T. O.; Chukwuemeka, P. O. Molecular docking studies of some selected gallic acid derivatives against five non-structural proteins of novel coronavirus. J. Genet. Eng. Biotechnol. 2021, 19, 1-14.

(26) Cherrak, S. A.; Merzouk, H.; Mokhtari-Soulimane, N. Potential bioactive glycosylated flavonoids as SARS-CoV-2 main protease inhibitors: A molecular docking and simulation studies. PLoS One 2020, 15, No. e0240653.

(27) Du, R.; Cooper, L.; Chen, Z.; Lee, H.; Rong, L.; Cui, Q. Discovery of chebulagic acid and punicalagin as novel allosteric inhibitors of SARS-CoV-2 3CL ${ }^{\text {pro }}$. Antiviral Res. 2021, 105075.

(28) Kaufer, A. M.; Theis, T.; Lau, K. A.; Gray, J. L.; Rawlinson, W. D. Laboratory biosafety measures involving SARS-CoV-2 and the classification as a risk group 3 biological agent. Pathology 2020, 52, $790-795$.

(29) Espín, J. C.; García-Conesa, T.; Tomás-Barberán, F. Biological significance of urolithins, the gut microbial ellagic acid-derived metabolites: The evidence so far. Evidence-Based Complementary Altern. Med. 2013, 2013, 270418.

(30) González-Barrio, R.; Truchado, P.; Ito, H.; Espín, J. C.; TomásBarberán, F. A. UV and MS identification of urolithins and nasutins, the bioavailable metabolites of ellagitannins and ellagic acid in different mammals. J. Agric. Food Chem. 2011, 59, 1152-1162.

(31) Tomás-Barberán, F. A.; González-Sarrías, A.; García-Villalba, R.; Núñez-Sánchez, M. A.; Selma, M. v.; García-Conesa, M. T.; Espín, J. C. Urolithins, the rescue of "old" metabolites to understand a "new" concept: Metabotypes as a nexus among phenolic metabolism, microbiota dysbiosis, and host health status. Mol. Nutr. Food Res. 2017, 61, 1500901.

(32) Cortés-Martín, A.; Selma, M. V.; Tomás-Barberán, F. A.; González-Sarrías, A.; Espín, J. C. Where to look into the puzzle of polyphenols and health? The postbiotics and gut microbiota associated with human metabotypes. Mol. Nutr. Food Res. 2020, 64, 1900952.

(33) del Rio, D.; Rodriguez-Mateos, A.; Spencer, J. P. E.; Tognolini, M.; Borges, G.; Crozier, A. Dietary (poly)phenolics in human health: Structures, bioavailability, and evidence of protective effects against chronic diseases. Antioxid. Redox Signaling 2013, 18, 1818-1892.

(34) Johnson, S. L.; Park, H. Y.; Vattem, D. A.; Grammas, P.; Ma, H.; Seeram, N. P. Equol, a blood-brain barrier permeable gut microbial metabolite of dietary isoflavone daidzein, exhibits neuroprotective effects against neurotoxins induced toxicity in human neuroblastoma sh-sy5y cells and Caenorhabditis elegans. Plant Foods Human Nutr. 2020, 75, 512-517.

(35) Myszka, D. G.; Rich, R. L. Implementing Surface plasmon resonance biosensors in drug discovery. Pharm. Sci. Technol. Today 2000, 3, 310-317.

(36) Nordin, H.; Jungnelius, M.; Karlsson, R.; Karlsson, O. P. Kinetic studies of small molecule interactions with protein kinases using biosensor technology. Anal. Biochem. 2005, 340, 359-368.

(37) Abdiche, Y. N.; Yeung, Y. A.; Chaparro-Riggers, J.; Barman, I.; Strop, P.; Chin, S. M.; Pham, A.; Bolton, G.; McDonough, D.; Lindquist, K.; Pons, J.; Rajpal, A. The neonatal Fc receptor $\left(F_{c} R n\right)$ binds independently to both sites of the IgG homodimer with identical affinity. mAbs 2015, 7, 331-343.

(38) Hagerman, A. E. Chemistry of tannin-protein complexation. In Chemistry and significance of condensed tannins; Springer, 1989, 30 (1), 323-333, DOI: 10.1007/978-1-4684-7511-1 20.

(39) Frazier, R. A.; Deaville, E. R.; Green, R. J.; Stringano, E.; Willoughby, I.; Plant, J.; Mueller-Harvey, I. Interactions of tea tannins 
and condensed tannins with proteins. J. Pharm. Biomed. Anal. 2010, 51, 490-495.

(40) Kumar, N.; Pratibha, P.; Neeraj, N. Functional properties of pomegranate peel in edible coating/film: A review. Int. J. Postharvest Technol. Innovation 2020, 7, 205-216.

(41) Howell, A. B.; D'Souza, D. H. The pomegranate: effects on bacteria and viruses that influence human health. Evidence-Based Complementary Altern. Med. 2013, 606212.

(42) Ismail, T.; Sestili, P.; Akhtar, S. Pomegranate peel and fruit extracts: A review of potential anti-inflammatory and anti-infective effects. J. Ethnopharmacol. 2012, 397-405.

(43) Yuan, G.; Lv, H.; Tang, W.; Zhang, X.; Sun, H. Effect of chitosan coating combined with pomegranate peel extract on the quality of pacific white shrimp during iced storage. Food Control 2016, $59,818-823$. 